\title{
Temporal and spatial variation of annual mean air temperature in arid and semiarid region in northwest China over a recent 46 year period
}

\author{
ShaoYong $\mathrm{CHEN}^{1,2^{*}}$, YuanYuan $\mathrm{SHI}^{2}$, YuZhen $\mathrm{GUO}^{2}$, YanXiang Zheng ${ }^{2}$ \\ ${ }^{1}$ Key Laboratory of Arid Climatic Changing and Reducing Disaster of Gansu, Key laboratory of Arid Climatic Changing and \\ Reducing Disaster of CMA, Institute of Arid Meteorology, CMA, Lanzhou 730020, China; \\ ${ }^{2}$ Meteorological Bureau of Baiyin, Baiyin 730900, China
}

\begin{abstract}
We analyzed the 1961-2006 mean surface air temperature data of 138 stations in China's northwest arid and semi-arid areas (CNASA), to measure climate change in terms of annual mean air temperature changes. We used methods of linear regression analysis, multinomial fitting, Empirical Orthogonal Function (EOF), Rotated Empirical Orthogonal Function (REOF), Mann-Kendall, Glide T-examination, wavelet analysis and power spectrum analysis. The results show that (1) the warming rate of the annual mean air temperature in CNASA was $0.35^{\circ} \mathrm{C} / 10$ a during the $1961-2006$ study period. Some places in the west part of Xinjiang and east part of the Qinghai plateau, which is impacted by the terrain of leeward slope, exhibit smaller increasing trends. However, the majority of region has shown distinct warming in line with general global warming; (2) The standard deviation of the annual mean temperature distribution is non-uniform. The south Xinjiang and east Qinghai-south Gansu areas show relatively small standard deviations, but the inter-annual variation in annual mean air temperature in the greater part of the region is high; (3) Inner Mongolia, Shaanxi, Gansu, Ningxia and Tarim Basin are the areas where the temperature changes are most sensitive to the environment. The degree of uniformity in annual mean air temperature increase is higher in the arid and semi-arid area. From the early 1970s, the trend in temperature changed from a decrease to an increase, and there was a marked increase in mean temperature in 1986. After that mean temperature went through a period of rapid increase. The entire area's 10 hottest years all occurred in or since the 1990 s, and $90 \%$ of various sub-districts' hottest years also occurred after 1990. The process of temperature change appears to have a roughly 5-year and a 10-year cycle; (4) Annual mean air temperature variation has regional differences. In Inner Mongolia-Xinjiang and ShaanxiGansu-Ningxia-Qinghai areas, the temperature variation in their northern areas was very different from that in their southern areas; (5) Using the REOF method we divided the region into 4 sub-regions: the Northern region, the Plateau region, the Southern Xinjiang region and the Eastern region. The region's annual mean air temperature transition has regional differences. The Plateau and Southern Xinjiang regions got warmer steadily without any obvious acceleration in the rate of warming. The Northern region's warming started about 5-years earlier than that of the low latitude Eastern region. The 'Startup region' of the Qinghai-Tibet Plateau, appears to undergo temperature changes 3 to 10 years earlier than the other regions, and exhibits inter-decadal variations 1 to 2 years ahead of the other regions.
\end{abstract}

Keywords: northwest area of China; annual mean air temperature; climatic warming

\section{Introduction}

With increasingly obvious global warming, the global environmental problems associated with climate change have attracted more and more attention of the scientific community, governments and the public. The fourth IPCC appraisal report indicates that the global mean air temperature has risen $0.74^{\circ} \mathrm{C}$ over the hundred years 1906-2005, the linear gradient in the recent 50 years is $0.13^{\circ} \mathrm{C} / 10 \mathrm{a}, 11$ of the warmest 12 years since the year 1850 occurred between 1995 and

\footnotetext{
Received 2009-12-24, accepted 2010-03-19 doi: 10.3724/SP.J.1227.2010.00087

*Corresponding author: ShaoYong CHEN (E-mail: csy505@tom.com)
} 
2006 (IPCC, 2007). By estimate global warming will continue in the 21 st century, due to the release of many kinds of greenhouse gases into the atmosphere. It can be predicted that the average warming of the Earth's surface is $1.1^{\circ} \mathrm{C}$ to $6.4^{\circ} \mathrm{C}$. Similar to the warming of the Earth's surface, the air temperature in China has shown a remarkable tendency to rise in recent years. The mean surface air temperature in the whole of China rose $0.79^{\circ} \mathrm{C}$ in the last 100 years, with a warming rate of about $0.08^{\circ} \mathrm{C} / 10 \mathrm{a}$. The mean air temperature rise in northwest China has been a little higher than the global average value for the corresponding period (Tang and Ren, 2005; Ding et al., 2007; Qin et al., 2007). The rising amplitude of the average surface air temperature in China is about $1.1^{\circ} \mathrm{C}$, with a warming rate close to $0.22^{\circ} \mathrm{C} / 10 \mathrm{a}$. This is remarkably higher than the global or hemisphere average warming rate over the same period (Ding et al., 2004; Ren et al., 2005). There are many researches on surface air temperature variation, which use different methods to prove climate warming is occurring (Tu et al., 2000; Chen and Liu, 2002; Ma et al., 2003; Cheng and Wang, 2004; Qian et al., 2004; Wang et al., 2004a; Wang et al., 2004b; Wang and Fang, 2004; Xu and Wei, 2004; Yuan and Mu, 2004; Zuo et al., 2004; Ding et al., 2005). The east monsoonal area, the arid and semiarid northwest region and the Qinghai-Tibet Plateau in the southwest form the different regional climatic characteristic in China and account for the complexity and differences in regional response to global climatic change. There has been much research on surface air temperature variation in the northwest arid region. Li et al. (2005) used air temperature data in January in the years 1961 to 1997 to analyze the spatial and temporal variations of annual mean air temperature in arid and semiarid areas in China and Mongolia. It was identified that the air temperature rose remarkably in winter in the region, and that the centre of the warming is distributed in the Linhe-Fuyun and Guaizi Lake area of the border area between China and Mongolia. Here the recent, average rising amplitude is more than $2.5^{\circ} \mathrm{C}$ over a 20 year period. The year 1977 was the pivotal year of turning warm from cold. There is a $3-4$ year cycle of annual mean air temperature in most of the areas in the region, there is even an 8 year cycle in some areas. Shi et al. (2003) indicate that the climate in the northwest is transforming from warm and dry to warm and wet. Ren et al. (2006) using data over period 1961 to 2000 to research the tendency of climate variation in the northwest in recent 40 years, considered that annual mean air temperature in this arid area was an upward trend of $0.22^{\circ} \mathrm{C} / 10 \mathrm{a}$, but the air temperature rose markedly after the year 1986. The arid and semiarid region in northwest China discussed in this article is a westerly climatic region separating from the east monsoon area. Using the surface observational data over the recent 46 years, we have concentrated particularly on the analysis of climatic warming characteristics such as air temperature transition, point of change and warmer years in the region, rather than repeating the existing research work in terms of data, area, methods and priorities. We offer a rational analysis of our conclusions, to provide recommendations for a regional response to climate warming in the arid and semiarid northwest region.

\section{Data and methods}

\subsection{Data}

We used data from the China Meteorological Administration, Meteorological Information Center for surface monthly mean air temperature over the year 1961-2006 from 138 stations in the arid and semiarid region in northwest China $\left(73.5^{\circ} \mathrm{E}-111.8^{\circ} \mathrm{E}, 31.5^{\circ} \mathrm{N}-\right.$ $49.3^{\circ} \mathrm{N}$ ), including western Shaanxi, middle and western Inner Mongolia, Xinjiang, Qinghai and Gansu, which have integrated data (Fig. 1).

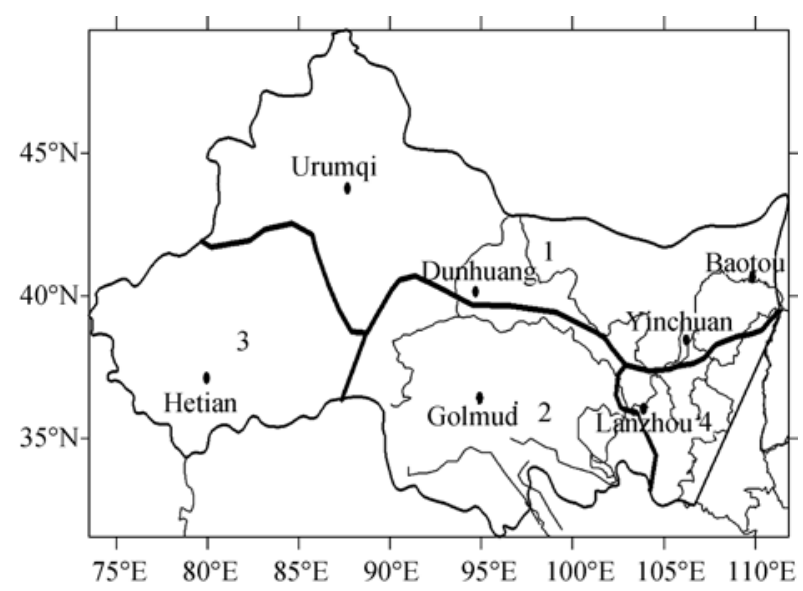

Fig. 1 Stations selected and the four climatic subregions of the annual average temperature within China northwest arid and semi-arid area (CNASA) 


\subsection{Methods}

\subsubsection{Linear regression analysis}

We used the following equation for the climatic factor as a function of time $t$ :

$$
y=\mathrm{a} t+\mathrm{b},
$$

where $\mathrm{a}$ and $\mathrm{b}$ are empirical constants calculated by least squares method using the observational data. The ' $a$ ' denotes slope of linear function, with plus and minus values reflecting an uptrend or downtrend of $y$. The magnitude of ' $a$ ' values reflect the velocity of upward or downward change over time $(t)$, that is, linear tendency in inter-annual variability of the climatic element. After calculating linear regression ' $a$ ', we tested correlation coefficient $r$ between time $t$ and variant $y$; if $r$ values were significant, we considered the tendency to have statistical meaning, among them, $r_{0.05}=0.291, r_{0.01}=0.376, r_{0.001}=0.470$.

\subsubsection{Cubic polynomial curvilinear fitting}

We used the following Cubic function to express the climatic element as a non-linear function of time $t$ :

$$
y=\mathrm{b}_{0}+\mathrm{b}_{1} t+\mathrm{b}_{2} t^{2}+\mathrm{b}_{3} t^{3},
$$

where $b_{0}, b_{1}, b_{2}$ and $b_{3}$ are empirical constant, calculated from observational data using least squares method. Short term climatic change (from several years to a dozen years scale) could be well reflected by Cubic function fitting curve (Wang, 1994), and according to interim extreme values from the Cubic function, we could analyze the transformation character of element change qualitatively. A minimum value would correspond to the time when the element value turned from descending to ascending; a maximum value would correspond to the element value turning from ascending to descending.
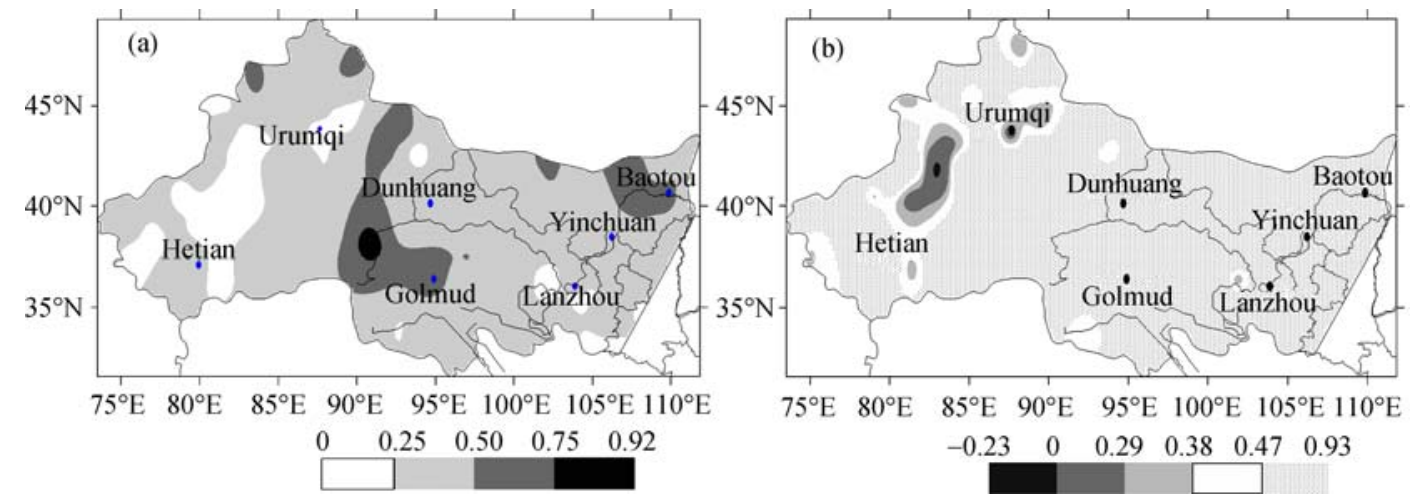

Fig. 2 The distribution of incalescence rate/10a (a) and remarkably incalescence areas (b) of long-term variation for annual average temperature in CNASA

\subsubsection{Abrupt climatic change analysis}

Mann-Kendall method (Fu and Wang, 1992) and Glide T-examination method were used for the analysis of abrupt climatic change.

\subsubsection{Periodic analysis}

MHAT wavelet (Lin and Deng, 1999; Stephane and Wen, 1992; Chen and Sun, 2006) and power spectrum were used for periodic analyses (Huang, 2000). In order to objectively and quantitatively analyze distribution and change characteristics of air temperature in the region using EOF and REOF methods (Li et al., 1997; Chen and Dong, 2006), we zoned the normalization annual mean air temperature data in the western arid and semiarid region.

\section{Results and discussion}

\subsection{Annual mean air temperature and its change characteristics}

3.1.1 Inter-annual change of annual mean air temperature

In Fig. 2a of spatial distribution of linear regression of annual mean air temperature we can find that during the years 1961-2006, there is a general uptrend of annual mean air temperature in arid and semiarid region in northwest China. The average air temperature warming rate across the whole region was $0.35^{\circ} \mathrm{C} / 10 \mathrm{a}$, with $95 \%$ of the stations showing significantly increased temperatures. The place that recorded the highest warming was Mangya in the Qaidam basin, the warming rate of which is $0.92^{\circ} \mathrm{C} / 10 \mathrm{a}$. The places that recorded the second highest warming were Linhe in Inner Mongolia and Qijiaojing in Xinjiang, whose 
warming rate was $0.70^{\circ} \mathrm{C} / 10 \mathrm{a}$. Places where air temperature didn't increase significantly were mainly distributed in Altai, Urumqi, Yutian, Bayanbuluke, Alarcon and Kuche of Xinjiang, and Xining on the Eastern Qinghai plateau. The warming rate was generally $0.06-0.16^{\circ} \mathrm{C} / 10 \mathrm{a}$ (Fig. 2b). There was even a downtrend in Kuche in Xinjiang, although it was not significant.

The atmospheric circulation anomaly is the most direct factor which influences air temperature anomalies. According to the Eurasian westerly circulation index and characteristic subtropical high over the Western Pacific since the 1980s, the $500 \mathrm{hPa}$ mid-latitude meridional circulation is weak, zonal circulation is strong, and subtropical highs entered a persistently strong period at the same time. Those conditions led to decreased southward movement of cold air and increased air temperatures in most areas of China. The local non-apparent temperature ascend or descend in Xinjiang may be related to topography.

Western Xinjiang is ringed by a series of high mountains. The central range is the lofty Tianshan Mountians, which will produce downdrafts when the west wind negotiates the mountains, then warming by forming fohn effect at the eastern end of the mountains.

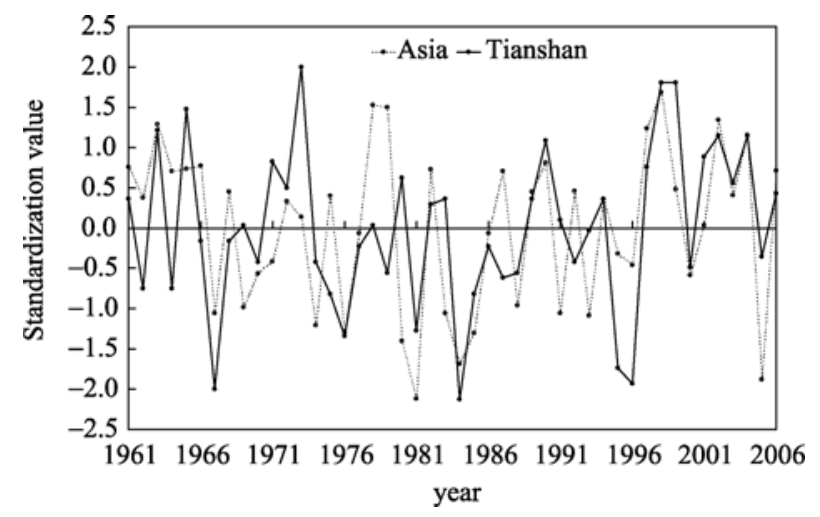

Fig. 3 The inter-annual variation of Xinjiang partial annual mean temperature and Asian zonal circulation index
The stronger the west wind is, the stronger the subsidence warming is (Tang et al., 1988). We chose the 3 stations of Bayanbuluke, Alaer and Kuche in the inapparent warming and cooling region, calculated the regional average air temperature, compared and analyzed the sequence with the Asia zonal circulation index (Fig. 3), and then we can see in the Fig. 3 that the vibration tendency of them are basically the same, correlation coefficient is 0.522 , it is more than a confidence degree level of $99 \%$. In the 1960 s, the west wind is stronger, so the lee subsidence is stronger, causing the raise of air temperature. During the 1970s to the 1980 s lee subsidence weakened with the reduction of west wind, it causes the fall of air temperature. After the later period of 1980 s, air temperature increased as the west wind strengthened.

An EOF analysis was performed on the air temperature field of 138 stations in the region over a 46 year period. The accumulative variance contribution rate of the first 10 spatial components or load vectors (LV) was found to be $94.09 \%$ of the total variance. The first 2 of the 10 contribute $79.96 \%$ of the total variance (Table 1), which indicates that the EOF convergent velocity of the annual mean air temperature is faster in the western arid and semiarid region. Using the empirical criterion of North et al. (1982), we could adequately explain the main features of the spatio-temporal variation of air temperature in the region by reference to only the first 2 load vectors (LV1-LV2) and the corresponding temporal components or principal components (PC1-PC2).

The variance contribution rate of the first spatial type reached $68.50 \%$, and basically summarized the main information of the air temperature field (Table 1). On the load vector diagram, load value of a certain point indicates the degree of correlation between air temperature of the point and the corresponding principal components sequence. If the absolute value of the load value of the point is bigger, air temperature of

Table 1 Variance contribution rates (\%) of the principal components of EOF and REOF analyses of annual mean temperature over CNASA

\begin{tabular}{lccccccccccccc}
\hline & 1 & 2 & 3 & 4 & 5 & 6 & 7 & 8 \\
\hline EOF analysis & 68.50 & 11.46 & 3.94 & 2.61 & 2.13 & 1.69 & 1.21 & 1.07 & 0.77 & 0.72 \\
PC cumulative contribution rate & 68.50 & 79.96 & 83.90 & 86.51 & 88.64 & 90.33 & 91.54 & 92.60 & 93.37 & 94.09 \\
REOF analysis & 28.62 & 24.75 & 13.54 & 13.30 & 5.54 & 2.95 & 1.72 & 1.40 & 1.38 & 0.86 & 95 \\
RPC cumulative contribution rate & 28.62 & 53.37 & 66.91 & 80.22 & 85.75 & 88.70 & 90.43 & 91.83 & 93.20 & 94.07 \\
\hline
\end{tabular}




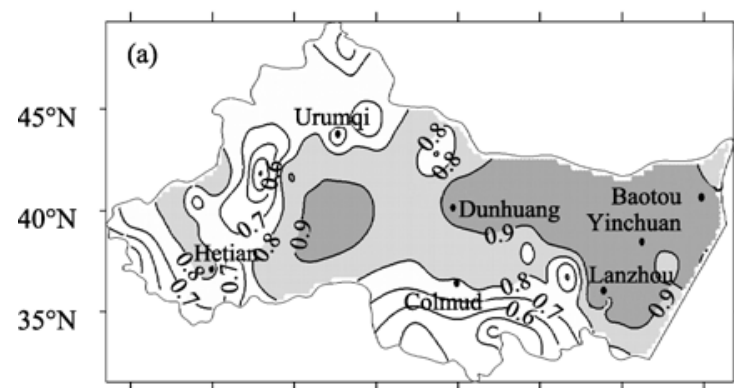

$75^{\circ} \mathrm{E} \quad 80^{\circ} \mathrm{E} \quad 85^{\circ} \mathrm{E} \quad 90^{\circ} \mathrm{E} \quad 95^{\circ} \mathrm{E} \quad 100^{\circ} \mathrm{E} \quad 105^{\circ} \mathrm{E} \quad 110^{\circ} \mathrm{E}$

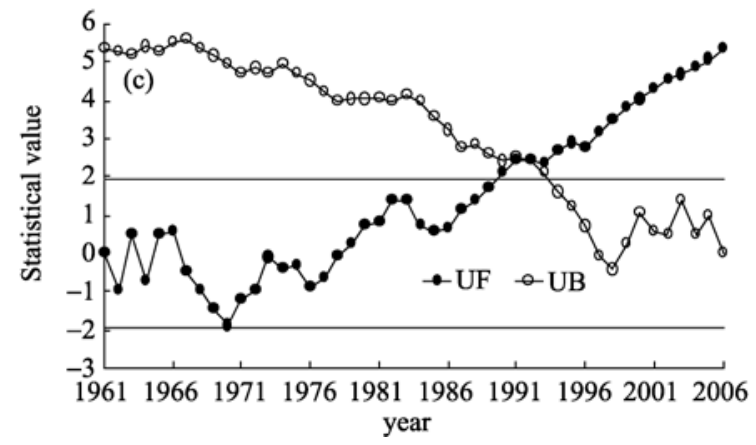

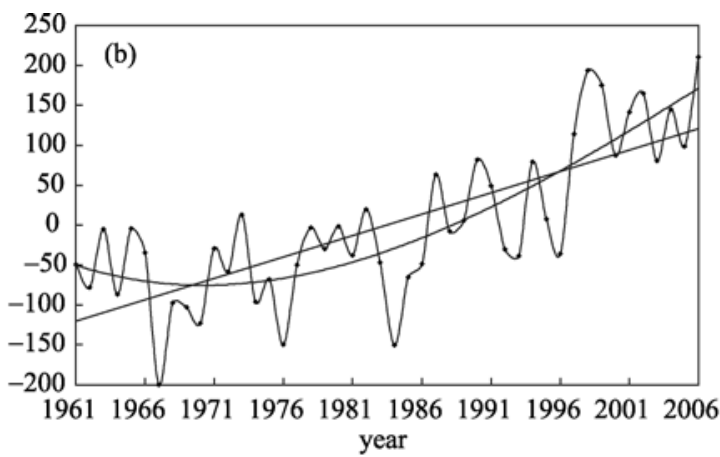

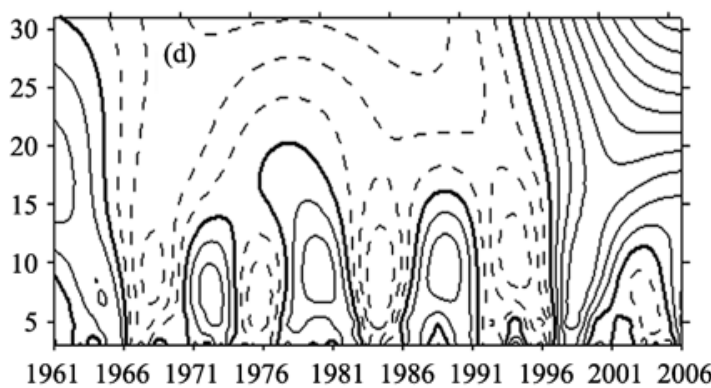

Fig. 4 The LV1 (a), its PC1 (b) and M-K check curve chart (c) and wavelet (d) of annual average temperature in CNASA

the point is easily becoming warmer or cooler; the variation is more sensitive and vice versa. Figure 4 shows the first load vector LV1. There are consistent positive values over the whole region, and the load values of $98 \%$ of stations are between 0.38 and 0.98 $(\alpha=0.01)$. There is positive correlation over the whole region, especially for the Inner Mongolia, Shaanxi, Gansu, Ningxia and Tarim Basin, where there is the biggest correlation coefficient, between 0.85 and 0.98 . In these regions air temperature change has been the greatest, whether warming or cooling.

The correlation coefficient of the first-order linear tendency of PC1 temporal curve (Fig. 4b) was 0.752, which reflects a remarkable extreme warming tendency in the northwest in winter. The correlation coefficient between PC1 and the Cubic polynomial curve fitting function was $0.813(\alpha<0.001)$. From this it represents that the Cubic function has ability to a varying trend of the original sequence. The Cubic function of PC1 was at a minimum in the early 1970s, showing that the cooling to warming transition happened in the early 1970s in the western arid and semiarid region.

LV1 showed positive load values over the whole region, the peak or valley value on the corresponding PC1 temporal sequence curve is the warmer or cooler year. In order, the years 2006, 1998, 1999, 2002, 2004, 2001, 1997, 2005, 2000, and 1990 were the 10 warmest years over the whole region in the past 46 years, which all appeared since 1990. While, in order, the years 1967, 1984, 1976, 1970, 1969, 1968, 1974, 1964, 1962, and 1975 were the 10 coolest years in turn over the whole region in the past 46 years.

Judging from the $\mathrm{M}-\mathrm{K}$ curve graph (Fig. 4c) and Glide T-examination combined with Fig. 3b, the annual mean air temperature in the northwest arid and semiarid region represent a conspicuous warming tendency, with the air temperature showing an increasing tendency since 1969. There has been an abrupt change in 1986, since when the air temperature has increased through an exceptional warming period.

On the corresponding wavelet analysis (Fig. 4d), the quasi 5 -year and 10-year cycles are both striking $(\alpha<0.05)$. Judging from changes in the inter-annual variations between one 10-year period and the next, the amplitude of air temperature variation increases over time. Between increasing amplitude towards the warmer phase, there are 5 periods of lower air temperature phase: 1966-1970, 1974-1977, 1983-1986, 1992-1996, and 2002-2004. There are 5 periods of higher air temperature: 1961-1965, 1971-1974, 1978-1982, 1987-1991 and 1997-2001. We are in one 
of the higher period in 2010. Judging from more than 15 years of climatic change, the tendency of the air temperature is at higher lever.

3.1.2 Standard deviation of annual mean air temperature

The standard deviation of air temperature in the region is generally between $0.5^{\circ} \mathrm{C}$ and $1.4^{\circ} \mathrm{C}$. The largest values, above $0.8^{\circ} \mathrm{C}$, appear in the northern Xinjiang, eastern section of the Tianshan Mountains, western Qinghai and Inner Mongolia. In these areas year-toyear variations in air temperature are unstable. The lower values, less than $0.6^{\circ} \mathrm{C}$, appear in the southern Xinjiang, eastern Qinghai, and southern Gansu. Here year-to-year variation of air temperature is relative stable.

\subsection{Spatial difference of annual mean air tem- perature in arid and semiarid region}

The contribution of the rate of variance of the second spatial type LV2 of annual mean air temperature deviation was $11.46 \%$. The main character of spatial distribution of LV2 (Fig. 5a) is that the zero line (thick black line) representing a general southwest-northeast direction from the north of Qinghai-Tibet Plateau to the northern part of Inner Mongolia. LV2 has negative values in Xinjiang and Inner Mongolia, and positive values in Shaanxi, Gansu, Ningxia and Qinghai. Thus, in the northwest of the region air temperature anomaly and the PC2 sequence have a negative correlation, whereas they have a positive correlation in the southeast; air temperature variation in the northwest and southeast shows opposite tendencies. PC2 has no significant uptrend (Fig. 5b), but the correlation coefficient between PC2 and its Cubic function shows a significance of $\alpha=0.01\left(R^{2}=0.396\right)$. The values for Cubic

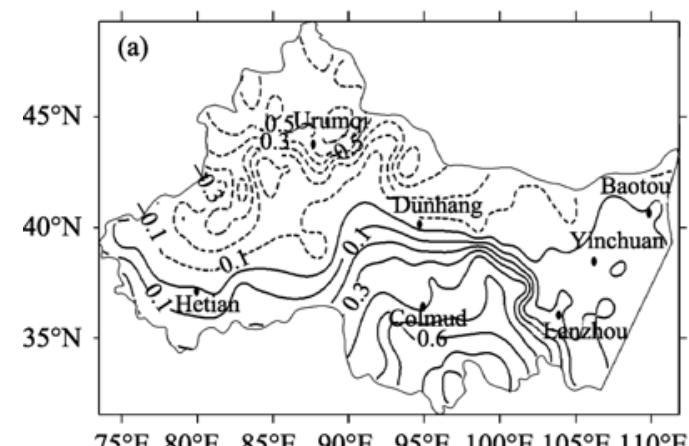

$75^{\circ} \mathrm{E} \quad 80^{\circ} \mathrm{E} \quad 85^{\circ} \mathrm{E} \quad 90^{\circ} \mathrm{E} \quad 95^{\circ} \mathrm{E} \quad 100^{\circ} \mathrm{E} 105^{\circ} \mathrm{E} 110^{\circ} \mathrm{E}$ function for the years 1969-1981 and 1998-2006 are positive, whereas the values for 1961-1965 and 1985-1997 are negative. It shows that 1961-1965 and 1985-1997 were years of high temperatures in Inner Mongolia-Xinjiang area and mainly low temperatures in the Shaanxi-Gansu-Ningxia-Qinghai area, while the years 1969-1981 and 1998-2006 showed the opposite, with low temperatures in the Inner Mongolia-Xinjiang area and mainly higher temperatures in the Shaanxi-Gansu-Ningxia-Qinghai area.

\subsection{REOF analysis of annual mean air tempera- ture in arid and semiarid region}

We analyzed element anomaly and areal sensitivity to change using REOF. To further determine details of anomaly partition of annual mean air temperature and to provide an objective basis for climatic partitioning in the region, we undertook a REOF analysis on the first $10 \mathrm{LV}$ components on the basis of the earlier EOF analysis. The cumulative contribution variance of the first 4 components in the REOF analysis totaled $80.22 \%$ (Table 1). The contribution to the variance of the fifth component fell sharply to $5.54 \%$, and after that each component was less than $3 \%$. So we chose the first four fields of rotation load vectors for analysis to obtain four major spatial anomaly regions for annual mean air temperature (Fig. 6).

\subsubsection{Air temperature anomaly partitioning}

In the first anomaly region RLV1 (Fig. 6a) has mainly negative values, which account for $28.62 \%$ of the total variance. The area of the highest values mainly includes Inner Mongolia, northern Ningxia, western Gansu and northern Xinjiang, the centre of which is at Altai in Xinjiang $\left(47^{\circ} 44^{\prime} \mathrm{N}, 88^{\circ} 05^{\prime} \mathrm{E}\right)$, with a maximum

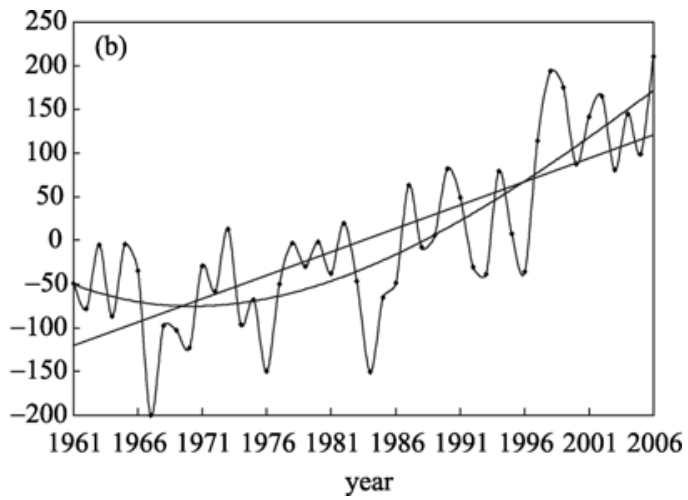

Fig. 5 The LV2 (a) and PC2 (b) of annual average temperature in CNASA 


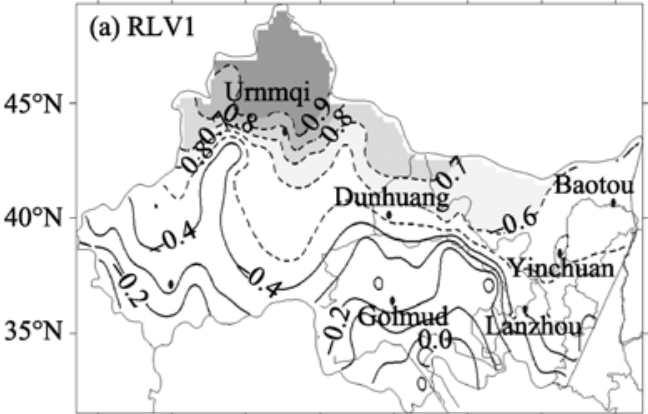

$75^{\circ} \mathrm{E} \quad 80^{\circ} \mathrm{E} \quad 85^{\circ} \mathrm{E} 90^{\circ} \mathrm{E} \quad 95^{\circ} \mathrm{E} 100^{\circ} \mathrm{E} 105^{\circ} \mathrm{E} 110^{\circ} \mathrm{E}$

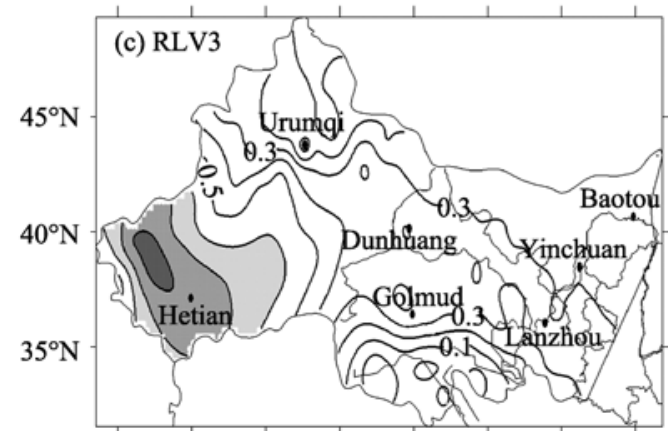

$75^{\circ} \mathrm{E} \quad 80^{\circ} \mathrm{E} \quad 85^{\circ} \mathrm{E} 90^{\circ} \mathrm{E} \quad 95^{\circ} \mathrm{E} 100^{\circ} \mathrm{E} 105^{\circ} \mathrm{E} 110^{\circ} \mathrm{E}$
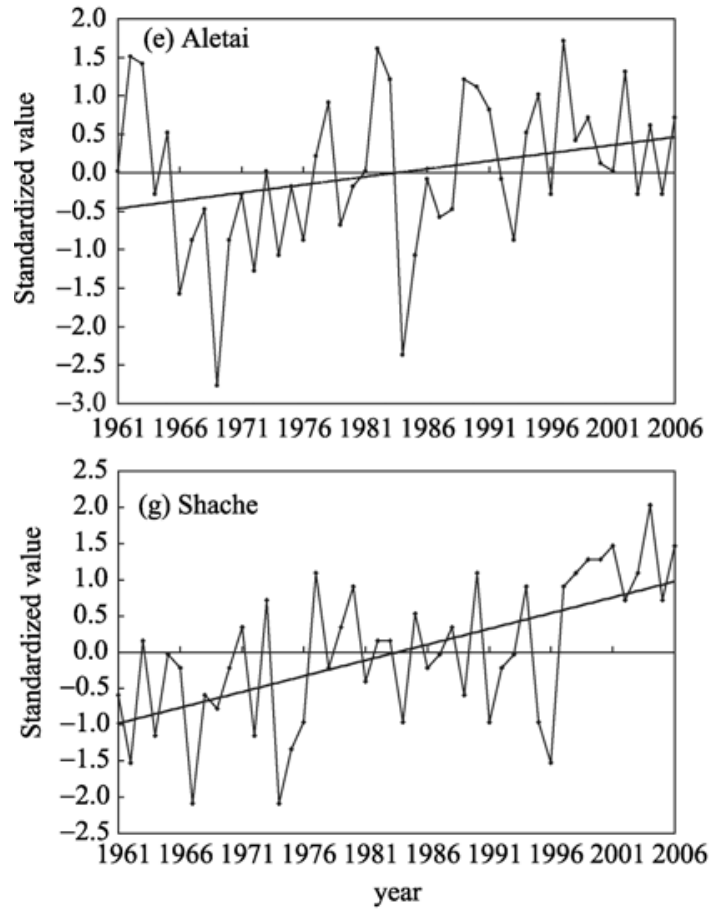

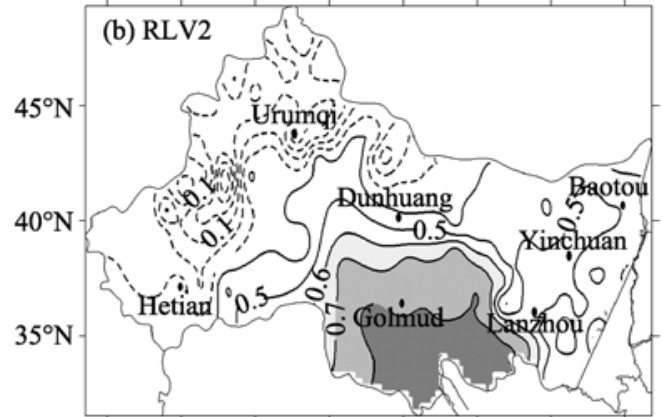

$75^{\circ} \mathrm{E} \quad 80^{\circ} \mathrm{E} \quad 85^{\circ} \mathrm{E} 90^{\circ} \mathrm{E} \quad 95^{\circ} \mathrm{E} 100^{\circ} \mathrm{E} 105^{\circ} \mathrm{E} 110^{\circ} \mathrm{E}$

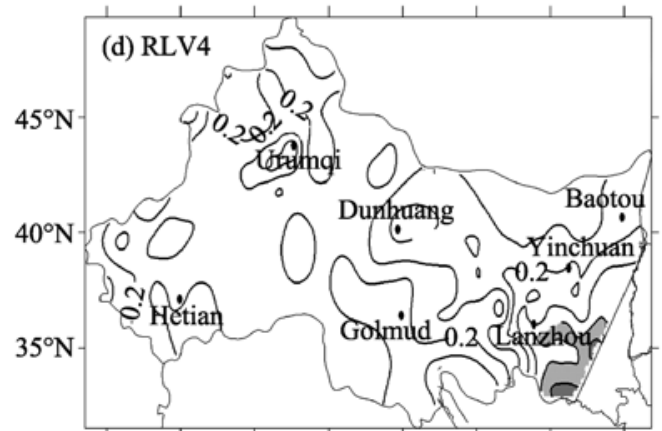

$75^{\circ} \mathrm{E} \quad 80^{\circ} \mathrm{E} \quad 85^{\circ} \mathrm{E} 90^{\circ} \mathrm{E} \quad 95^{\circ} \mathrm{E} 100^{\circ} \mathrm{E} 105^{\circ} \mathrm{E} 110^{\circ} \mathrm{E}$
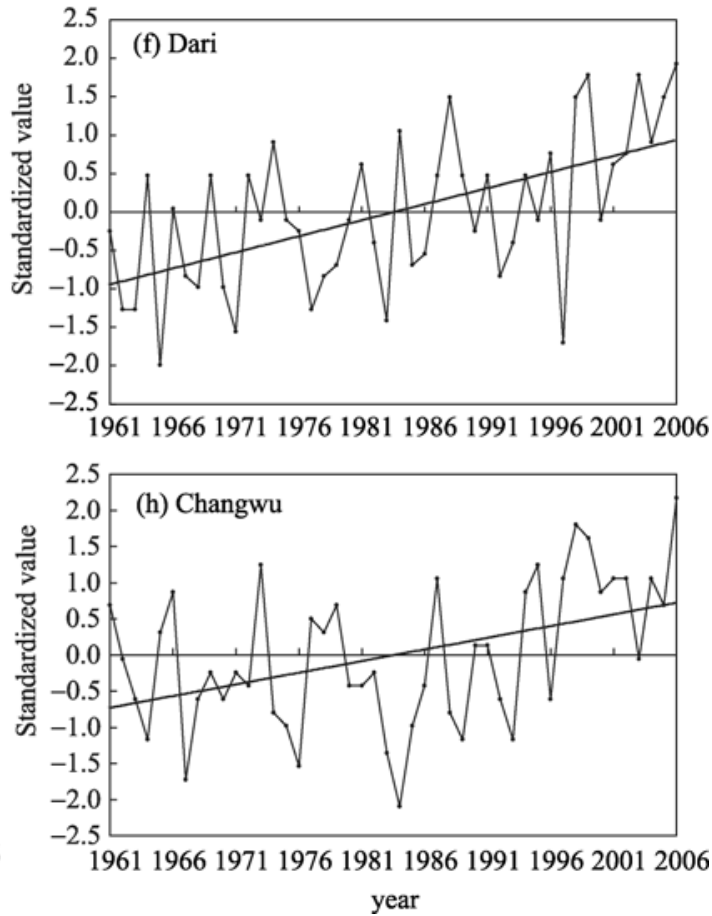

Fig. 6 The first 4 loading vectors (a-d) and their corresponding representative stations (e-h) of annual average temperature REOF in CNASA. Shaded part means areas which RLV>0.6.

absolute value RLV of -0.95 . This indicates that these are the most sensitive areas of air temperature anomaly in arid and semiarid region, which we called the Northern region.

The second anomaly region RLV2 (Fig. 6b) shows mainly positive values, which account for $25.75 \%$ of the total variance. This area with $\mathrm{RLV}>0.6$ values mainly includes Qinghai plateau, with the largest value at Dari in Qinghai $\left(33^{\circ} 45^{\prime} \mathrm{N}, 99^{\circ} 39^{\prime} \mathrm{E}\right)$, where the RLV value is 0.95 . This is the secondary sensitive area 
of air temperature anomaly in the arid and semiarid region, which we call the Plateau region.

The third anomaly area RLV3 (Fig. 6c) has mainly positive values, which account for $13.54 \%$ of the total variance. This area with RLV $>0.6$ values is mainly in southern Xinjiang. Here the largest value is in Shache in Xinjiang ( $\left.38^{\circ} 26^{\prime} \mathrm{N}, 77^{\circ} 16^{\prime} \mathrm{E}\right)$, with an RLV value of 0.85 . We called this Southern Xinjiang region.

The fourth anomaly region RLV4 (Fig. 6d) shows mainly positive values, and accounts for $13.30 \%$ of the total variance. This area with RLV $>0.6$ is mainly in western Shaanxi-Longnan, with the largest value at Changwu in Shaanxi $\left(35^{\circ} 12^{\prime} \mathrm{N}, 107^{\circ} 48^{\prime} \mathrm{E}\right)$, where the RLV value is 0.79 . We called this the Eastern region.

According to the related degree of air temperature anomaly in northwest arid and semiarid region and the range of 0.55 isopleths of the first 4 RLVs (Fig. 5a-d), we divided the region into 4 sub-regions (Fig. 1) and called them Northern region, Plateau region, Southern Xinjiang region and Eastern region respectively; they can also be abbreviated to Regions I, II, III and IV.

3.3.2 Temporal change of air temperature anomaly in each region

The peak value stations of RLV1-RLV4 can be employed to represent the climatic characteristic in their sub-regions, reflecting temporal change of air temperature in each of these abnormal regions. We analyzed the temporal change of air temperature anomaly in each region according to the normalization sequence of air temperature in the representative stations (Fig. 6e-h).

(1) Transformation characteristic We analyzed the transition of air temperature change in each region based on the plots of the Cubic curve. The annual mean air temperature of the Northern region showed an uptrend from the mid 1970s but this changed to a downtrend in the late 1990s. The air temperature increased monotonously in the Plateau region and Southern Xinjiang region, starting with a gentle trend in the 1970s and 1980s, but increasing sharply after the 1990s. Annual mean air temperature decreased in the Eastern region from the early 1960s to the early 1980s and increased since then. It can be seen that there are sub-regional differences in changes to annual mean air temperature in western arid and semiarid region. The air temperature has increased monoto- nously without any obvious sign of slowing in the Plateau region and Southern Xinjiang region; the temperature increases in the Northern region started roughly 5 years earlier than in the lower-latitude Eastern region.

(2) Characteristic of the warmer or cooler years The World Meteorological Office (WMO) uses the criterion that the measured deviation has to be larger than, or equal to, 2 times the standard deviation to be classified as a climate anomaly. By that standard deviations that we have calculated of between 1.5 and 1.9 times the standard deviation approximate to climate anomaly. We have chosen the value of 1.5 times the standard deviation from air temperature curves for each of the representative stations (Altai, Dari, Shache and Changwu) to indicate abnormal warmer or cooler years in each sub-region (Table 2). For example, in the Northern region the order of the first 3 years with the most obviously warmer temperatures is 1997, 1982, and 1962; the order of the first 3 most obviously cooler years is 1969,1984 , and 1966. Representative years for the four sub-regions are shown in Table 2 for the details. Note than $86 \%$ of the warmest years have occurred since 1990.

Table 2 Years with most obvious annual mean air temperature anomaly over sub-regions of the CNASA

\begin{tabular}{lcc}
\hline Sub-region & Anomalous form & Year \\
\hline \multirow{2}{*}{ Northern region } & hot & $1997,1982,1962$ \\
& cool & $1969,1984,1966$ \\
Plateau region & hot & $2006,2003,1999,2005,1998$ \\
Southern & cool & $1965,1997,1971$ \\
Xinjiang region & hot & $2004,2006,2001$ \\
& cool & $1967,1974,1962,1996$ \\
Eastern region & hot & $2006,1998,1999$ \\
& cool & $1984,1967,1976$ \\
\hline
\end{tabular}

(3) Change characteristic Changes were assessed using the $\mathrm{M}-\mathrm{K}$ test and Glide T-examination of Figs. 6e-h. The following results can obtained from the analysis:

( i ) 1969 had the lowest annual mean air temperature in 46 years in the Northern region, with air temperature increasing from 1970 and that change accelerating in 1987. Present air temperature is still part of that period of increasing temperature.

(ii ) In the Plateau region air temperature was fluc- 
tuating increase and temperature change accelerated in 1984, beginning a strong warming period.

(iii) In Southern Xinjiang region air temperature was fluctuating increase, particularly from 1977 and temperature change accelerated in 1996, commencing a strong warming period.

(iv) Air temperature in 1984 was the lowest in the Eastern region. It increased from 1985 and temperature change accelerated in 1994. It can be seen that rapid change in annual mean air temperature starts from the plateau. The order is Plateau region $>$ Northern region $>$ Eastern region $>$ Southern Xinjiang region. Rapid temperature change in other regions was 3-10 years later than the Plateau region.

(4) Inter-decadal variations As early as 1980, comparative analysis of climatic change in the Qinghai-Tibet Plateau, Qilian Mountains and east of China first proposed that the Qinghai-Tibet Plateau might be the 'Startup region' of climate change in China (Tang et al., 1984). Since then the concept of 'Startup region' has been further recognized (Feng et al., 1998). There is a school of thought that decade scale temperature waves propagate from the Qinghai-Tibet Plateau to east and north, and 4-8 years later in eastern China than in the southeastern plateau. Year-to-year analysis of change and correlation with delays in change of air temperature on the Qinghai plateau and other regions in the west will reveal whether and how long this priming effect still exists. Using air temperature wavelet exploded views of each representative station (figures not shown), we analyzed the wave peak change of a moving scale of up to 10 years duration. All results showed that air temperature changed in other regions in the northwest is 1-2 years later than in plateau region. In addition, calculated correlation coefficients of air temperature sequence in each sub-region were 1-10 years delayed compared to plateau-representative stations (Fig. 7). It can be seen that the maximum correlation coefficient is obtained on a 1-year lag between the Northern region, Southern Xinjiang region and the Plateau region, which are 0.38 and 0.36 respectively; the maximum correlation coefficient of 0.33 is obtained on a 6-year lag between the Eastern region and the Plateau region. All these correlations have significance $>95 \%$.

Whether assessed by temperature change characteristics or inter-decadal variations, air temperature change in the Plateau region occurs ahead of the other regions, which supports the concept of the Plateau region as a 'Startup region' of climatic change.

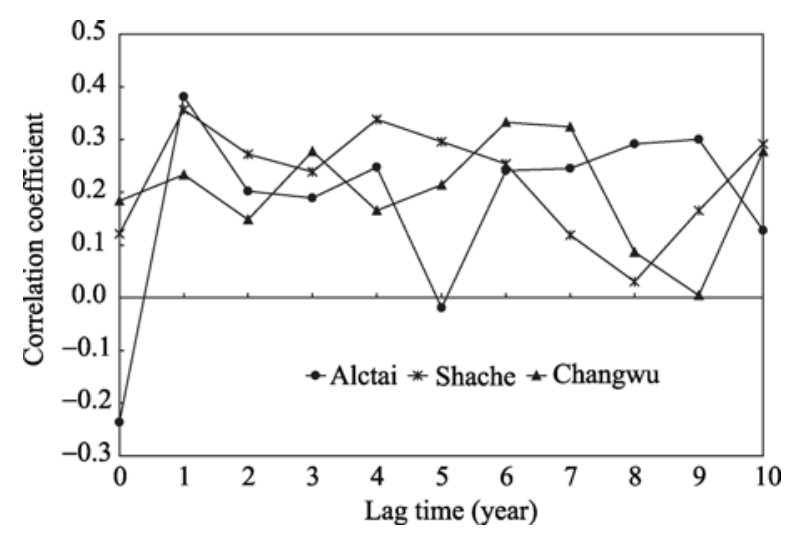

Fig. 7 Lag correlation coefficient of annual mean temperature of Qinghai plateau and other area representative station

\section{Conclusion}

(1) The warming rate of the annual mean air temperature is $0.35^{\circ} \mathrm{C} / 10$ years in the arid and semi-arid region of northwest China in a recent 46 year period (1961-2006). Air temperature has increased significantly in most of the region, responding synchronously to global warming. However, topography (high terrain and leeward slopes) has influenced some areas, and part of Xinjiang and the eastern Qinghai plateau have shown no significant upward trend in annual mean air temperature. Kuche in Xinjiang has shown a local, non-significant downward trend in temperature.

(2) Relative variability and standard deviation of the annual mean air temperature show differences and uneven distribution across the region. Except for relatively small areas in Southern Xinjiang and the Haidong-Longnan area, annual mean air temperature is quite variable from year to year in most of the remaining parts of the arid and semi-arid region.

(3) Inner Mongolia, Shaanxi, Gansu, Ningxia and the Tarim Basin are the most sensitive areas to temperature change in the region. The evolution of annual mean air temperature in arid and semi-arid region has high level of consistency. A transformation from cooling to heating up has occurred since the early 1970s, with the air temperature showing a significant increase in change in 1986 which commenced a significant warming period. The region's 10 warmest years all occurred in or after the 1990s; most of the 
abnormal warmer years in each sub-region appeared after the 1990s; the changes to air temperature exhibit 5 -year and 10-year cycles. According to observations of the levels of change, the trend in air temperature is still upward.

(4) Sub-regional differences exist in changes in the annual mean air temperature. In some years the variation in temperature in the Inner Mongolia-Xinjiang area was opposite that in the Shaanxi-GansuNingxia-Qinghai area. In 1961-1965 and 1985-1997 air temperatures were higher in the Inner Mongolia-Xinjiang area and mainly lower in the ShaanxiGansu-Ningxia-Qinghai area, while in 1969-1981 and 1998-2006 conditions were reversed, with lower temperatures in the Inner Mongolia-Xinjiang area and mainly higher temperatures in the Shaanxi-GansuNingxia-Qinghai area.

(5) According to the REOF analysis, the annual mean air temperature anomalies in the region can be

\section{References}

Chen S Y, Dong A X. Study on climatic change and anomaly of low cloud amount over Qilian Mountain Area. Plateau Meteorology, 2006, 25(3): 545-548

Chen S Y, Sun B Q. The climatic variety and agriculture influence of frost in Baiyin. Journal of Gansu Sciences, 2006, 18(4): 46-49.

Chen W H, Liu Y X. The seasonal characteristics of climatic change trend in China from 1951 to 1997. Plateau Meteorology, 2002, 21 (3): $251-257$.

Cheng S L, Wang N A. Study on air temperature change in Lanzhou City in recent 70 years. Arid Land Geography, 2004, 27 (4): 558 - 563.

Ding Y H, Dong W J, He J H, et al. Asian monsoon and its effect on China climate and environmental changes. In: Qin D H, Ding Y H, Su J L. Changes of Climate and Environment in China (Vol. 1). Beijing: Science Press, 2005. 398-454.

Ding Y H, Ren G Y, Shi G Y, et al. National assessment report of climate change (I): climate change in China and its future trend. Advances in Climate Change Research, 2007, 3 (suppl.): 1-5.

Ding Y H, Wang Z Y, He J H, et al. An updating analysis of the climate change in China in recent 50 years. Acta Meteorologica Sinica, 2004, 62 (2): 228-236.

Feng S, Tang M C, Wang D M. New envidence for Qinhai-Tibet Plateau being the startup region of clamitic change in China. Chinese Science Bulletin, 1998, 43(6): 633-636.

Fu C B, Wang Q. The definition and detection of the abrupt climatic change. Scientia Atmospherica Sinica, 1992, 16 (4): 482 -493. divided into 4 sub-regions: the Northern region, Plateau region, Southern Xinjiang region and Eastern region. These regions exhibit differences in the timing of their turning points in annual mean air temperature. Air temperature increased monotonously in the Plateau region and Southern Xinjiang region and has no obvious turning point, while a turning from cooler to warmer temperatures is obvious in the Northern region, and occurred 5 years earlier than in the lower-latitude Eastern region.

The 'Startup region' of the Qinghai-Tibet Plateau, appears to undergo temperature changes 3 to 10 years earlier than the other regions, and exhibits inter-decadal variations 1 to 2 years ahead of the other regions.

\section{Acknowledgements}

This research was supported by National Natural Science Foundation of China (40775057).

Huang J Y. Climatic Statistics and Forecast Methods. Beijing: China Meteorological Press, 2000. 126-145.

IPCC. Summary for Policymakers of the Synthesis Report of the IPCC Fourth Assessment Report. Cambridge, UK: Cambridge University Press, 2007.

Li D L, Xie J N, Wang W. A study of summer precipitation feature and anomaly in Northwest China. Scientia Atmospherica Sinica, 1997, 21(3): 331-340.

Li W Y, Qian Z A. Temporal and spatial feature analyses of winter and summer surface air temperature in CMASA, Part (I): January. Plateau Meteorology, 2005, 24(6): 889-897.

Lin Z S, Deng Z W. Research on Diagnosis of Wavelet Climate. Beijing: China Meteorological Press, 1999. 21-26.

Ma Z G, Fu C B, Ren X B, et al. Trend of annual extreme temperature and its relationship to regional warming in Northern China. Acta Geographica Sinica, 2003, 58 (suppl.): 11-20.

North G R, Thomas L B, Cahalan R F. Sampling errors in the estimation of empirical orthogonal functions. Monthly Weather Review, 1982, 110: 699-706.

Qian W H, Chen D L, Lin X, et al. Change trends of regional temperature and precipitation over China under background of global change. Climate Change News Letter, 2004, 3 (3): 8-9.

Qin D H, Chen Z L, Luo Y, et al. Updated understanding of climate change sciences. Advances in Climate Change Research, 2007, 3 (2): $63-73$. 
Ren C X, Yang D Y. Variations trend of climate of Northwest area in China in the last 50 years. Quaternary Sciences, 2006, 26 (2): 299-300.

Ren G Y, Guo J, Xu M Z, et al. Climate changes of Mainland China over the past half century. Acta Meteorologica Sinica, 2005, 63 (6): 942-956.

Shi Y F, Shen Y P, Li D L, et al. Discussion on the present climate change from warm-dry to warm-wet in Northwest China. Quaternary Sciences, 2003, 23 (2): 152-164.

Stephane M, Wen L H. Singularity detection and processing with wavelets. IEEE Transactions on Information Theory, 1992, 38 (2): 630-637

Tang M C, Li C Q, Zhang J. The climate change of Qinghai-Xizang plateau and its neighbourhood. Plateau Meteorology, 1988, 7(1): 39-49.

Tang G L, Ren G Y. Reanalysis of surface air temperature change of the past 100 years over China. Climatic and Environmental Research, 2005, 10 (4): 791-798.

Tang M C, Xu M C. Climatic variety of Qilian Mountain area. Plateau Meteorology, 1984, 3 (4): 21-33.
Tu Q P, Deng Z W, Zhou X L. Study on regional feature of China temperature variation. Acta Meteorologica Sinica, 2000, 58 (3): 288-296.

Wang S W. Climate System General Introduction. Beijing: China Meteorological Press, 1994.

Wang X D. Analysis on climate change and its influence in Shanxi, Gansu and Ningxia. Arid Land Geography, 2004a, 27 (10): 24-28.

Wang X J, Fang Z F. Surface air temperature in China and its relation to Arctic Oscillation Index. Plateau Meteorology, 2004b, 23 (suppl.): 80-88.

Wang Y, Li X, Miao Q L. Analyses on variety characteristics of temperature. Arid Land Geography, 2004, 27 (1): 41-46.

XU G Q, Wei W S. Climate change of Xinjiang and its impact on eco-enviroment. Arid Land Geography, 2004, 27 (1): 14-18.

Yuan Y J, Mu G J. Features of spring climate change in Tianshan Mountainous Area for the recent 40 years and comparison with that in plain area of Xinjiang. Arid Land Geography, 2004, 27(1): 35-40.

Zuo H C, Lv S H, Hu Y I. Variations trend of yearly mean air temperature and precipitation in China in the last 50 years. Plateau Meteorology, 2004, 23 (2): 238-244. 